\title{
SWARMING - DOCTRINARY-OPERATIONAL CONCEPT - POSSIBLE SOLUTION TO THE CHALLENGES OF THE CURRENT MILITARY CONFRONTATIONS
}

\author{
Aurelian RAȚIU \\ aurelian_ratiu@yahoo.com \\ “NICOLAE BÄLCESCU” LAND FORCES ACADEMY, SIBIU, ROMANIA
}

\begin{abstract}
:
Swarming is a current doctrinary-operational concept, by means of which one seeks to make the transition from a traditional, conventional, cumbersome, bureaucratic army to more numerous structures/units and of reduced dimensions, with remarkable firepower and mobility, which can act on an opponent from multiple directions simultaneously, leading to its increased vulnerability by disorientation and by the inability to concentrate their forces and effort to respond effectively.

The creation of forces able to act according to this conception implies radical changes in the modalities of organizing, acting and leading-coordinating, and last but not least, in the equipment of the military/units and in the organizational culture.
\end{abstract}

\section{KEYWORDS:}

Concentrated dispersion, omnidirectionality, pulsatory simultaneity, swarming

\section{Introduction}

At first glance, swarming as organization and action is typical to the animal world, but it can also be analysed from the perspective of human beings. Moreover, swarming in the human/military action cannot be modelled identically after the one existing in nature, but there are some lessons that can be learned.
In nature, the studies that have been carried out have identified several types of swarming and the principles of organization and of action, respectively.

Thus, a first form of swarming can be found in the hive- or nest-type organizations, this being best exemplified in the case of bees, ants and other social insects. These insects use swarming when 
attacking (the enemy or prey) from all directions, the ultimate goal being "the overwhelming/neutralization of the enemy". Although, under normal conditions, these insects move in linear formations, the moment the battle starts, they adopt the swarming tactics fast and with great flexibility.

The ants use the "swarming" tactics not only to obtain food or to defend their nest, but also to expand their territory through direct combat with other ants. These confrontations are of a complexity resembling human actions in military conflicts (Bernard, 2015).

\section{Theoretical-Methodological Considerations}

The swarming of ants also differs from other insects in that ants, armed with powerful mandibles and some acid-spraying capability, sustain their behavior throughout an engagement, and over an entire campaign. Bees, on the other hand, have individuals that can swarm just once, as the act of stinging results in the stinger's own death. In this respect, ants actions may provide a more useful model of what we call the sustainable operations of forces, while bees may resemble more the swarming of fire, as their stinging deaths seem analogous to "fire-and-forget" precision-guided munitions (Arquilla \& Ronfeldt, 2000, p. 26).

As far as swarming in human actions is concerned, specifically in military confrontations, and in order to be able to draw the relevant conclusions and learn the lessons, we made a content analysis, based on logical argumentation, of some important global battles of the past 200 years.

Thus, we can affirm and demonstrate the fact that in these battles the types of actions that were predominant were the frontal attack, the flanking manoeuvrel envelopment manoeuvre or the concentration of forces/effort, but in some cases, the characteristics of swarming as form of approach of the fight were also present. Sometimes these swarming tactics played a decisive role as in the case of the "U-boat
Submarines Campaign" (Trueman, 2016) and of the air defence operations against bombers during the Second World War.

Very often, swarming represented a multiplier of the combat power, which enabled, for example the Vietnamese forces, to attack an opponent that was superior from a numerical or technological point of view, this approach being based on a concept borrowed from the tactics of Genghis Khan.

These operations offered the possibility of presenting the principle of dispersion of the forces in correlation with the multidirectional and pulsatory attack in a very clear manner. From the perspective of the theoretical approach to the concept of swarming, the German strategist Otto Heilbrunn (1965, p. 45) had a first initiative, (as far we know) developing and presenting a systemic and systematic vision regarding this concept. He was preoccupied with the problem of increasing the chances of survival of the conventional forces in the tactical nuclear field specific to a possible major confrontation between the main actors of the Cold War. The solution proposed the application of new doctrinal elements by means of which the concept of concentrated dispersion of the forces was emphasized. This concept meant the development of new units of manoeuvre of small dimensions, scattered in the area of operations, but with a very good communication system, which would join efforts only at the appropriate moment to carry out an attack. After the attack, the forces would regroup and redeploy in a coordinated manner, preparing for the next attack or for defence, if the situation required it.

Furthermore, swarming is based on what Martin Libicki (1994, p. 28) called the "the many and small" and on David Gelernter's conception (1992, chapter 3) regarding a command and control element that can collect and process information in a short time and has the possibility to engage the available forces when needed.

Another interesting approach and 
close to the actual meaning of swarming is that of the two officers from the Chinese popular army, Qiao Liang and Wang Xiangsui $(1999$, p. 2), who talk about a war without rules and without restrictions, about innovative thinking in order to find ways to fight any opponent and any capabilities. The main idea of the two Chinese authors is that unrestricted war means multiple types of attacks on the social, economic, and political systems of the enemy, together with atypical attacks in the context of military irregular war planned/carried out in a certain rhythm and synchronicity, in order to weaken the opponent and to create opportunities for a favourable outcome.

\section{Identification of the Main Characteristics of Military Swarming}

By an objective assessment of the tackled issues, without any preconceived ideas or conjectural interpretations, we have come to the idea that swarming presents at least two fundamental requirements.

The first requirement is the ability of a force to hit the enemy from multiple directions, with a large number of small units of manoeuvre that are closely interconnected.

The second requirement refers to the fact that the force that applies the concept of swarming should not only engage the enemy, but should also constitute a sensorial organisation, providing the necessary information and permanent surveillance in order to create and maintain an overview image of the space of the battle.

Also, the main characteristic of swarming for achieving the goal of the military confrontation is not so much the physical destruction of the opponent, although numerous damages can occur, but it is especially based on the achievement of surprise and on its disorganization. The consequence would be the following: once the leadership system and the components of the deployed unit have lost their focus and freedom of action, they can no longer organize themselves to respond effectively to the attack.
Moreover, the key element of the military concept of swarming is the sustained pulsation, achieved either by distance firing or by engaging the manoeuvre units. According to this view, the structures that make up the force will occupy dispersed positions, but they will be capable to group and to concentrate their fire and forces to hit the important identified targets from all directions. After carrying out the hits, they will reposition themselves in an organized manner in order to avoid the possible countermeasures of the enemy, while, at the same time, being prepared to attack again when the circumstances permit it.

We infer the fact that swarming can be achieved both by means of the fire of those means of combat that can perform shootings at relatively large distances and by means of the combat military structures, engaging the enemy directly. Thus, with the advent of artillery, of missiles or of other high accuracy hitting systems, the concept of swarming can be put into practice by any army that possesses such systems, but the concept to which we refer is that involving forces, by close engagement.

The swarming achieved by means of forces was most present in guerrilla warfare (such as the operations conducted by the Chechens in the war of 1994-1996 against the Russians), and in the theatres of operations in Iraq and Afghanistan.

Actually, we believe that swarming by using forces is possible and perhaps it is the best solution to stabilize the situation in South-Eastern Ukraine (in the case of the conflict between the governmental Ukrainian forces and the pro-Russian separatists), although this capacity is not cultivated by the Kiev government. The strategy conceived by Ukraine was based on a classic "hammer and anvil" (Romania Military Site, 2014) manoeuvre where units of border guards were in the position of "anvil" along the common border with the Russian Federation, and the manoeuvre groups acting from the West were the "hammer" that struck the separatist forces. Taking into consideration the position of the Ukrainian forces, we can 
use the concept of swarming, as there existed the possibility of attacking the separatist forces from all the directions, at the same time resorting to the initiative of the manoeuvre units.

While the concept of "swarm" takes shape around an image of attackers (task forces, missiles, bombers) hitting a target from all the directions, less clear aspects have been identified, namely: if these attackers operate autonomously or follow an authority. In nature, swarms are composed of independent units whose actions are instinctive. In military conflicts, swarms may be independent or controlled. For example, the offensive of the Viet Cong forces, in January 1968 on the town of Têt (Sorley, 1999, p. 12); although they were coordinated from Hanoi, they enjoyed great freedom of action, consistent with the concept of Mao regarding the centralization for strategic purposes and the decentralization for tactical objectives (Griffith, 2005 p. 114). On the other hand, during the Battle of the Atlantic in World War II, the submarine U-boat group that attacked the convoys of supplies was tightly controlled by the direct orders of Admiral Doenitz (Arquilla \& Ronfeldt, 2000, p. 21).

From the case studies in the theatres of operations in Afghanistan, Iraq or Bosnia-Herzegovina, there appears the fact that swarming with forces depends heavily on the support of the local population, and a group of forces operating within a territory with hostile population may have major difficulties. Hence, one could infer that swarming operations would be easier to implement in the defensive, being more comfortable to fighting in known territory as, apparently, was the case of the Soviet antitank networks (minefields and artillery) that had a major role in defeating the Germans in the Battle of Kursk (OMICS International, 2014).

Referring again to the Ukrainian forces, these forces fight in a known territory, thus, the territory should not represent an obstacle. Moreover, a reduced ratio of fighters emerged from the formula rebel forces/controlled space requires a broader dispersion of the pro-Russian troops. Dispersion creates opportunities for multidirectional attack, i.e. swarming. Here we can only remember the saying of Frederick II of Prussia "in trying to defend everything, he defended nothing" (George, 2014). This is the situation that Kiev should take advantage of.

\section{Challenges in Developing the Concept of Swarming}

The new risks and threats in the security environment, the evolution of technology, the transition from the industrial age to the information age have brought profound changes in the physiognomy of war. In this context, swarming, one of the solutions within the reach of the actors in the field of security, requires more organizational innovations, new processes in the leadership system and new information and processing capabilities.

In the organizational field, and for the armies and the military decision-makers, the challenge of change from large and few units to "many and small" units is an important step. Over time, the principle of using a small number of large or very large military units was often applied in the universal military thinking. The army corps, the group of aircraft carriers as well as the expeditionary forces are all large scale and have been designed in order to be used in major military operations (e.g., the Gulf War of 1990-1991).

The division level structures, the largest unit of the land forces, were appropriately used in major conflicts, but in the unconventional or guerrilla ones, the large units were not effective. In order to particularize, there were many views regarding the conflict in Vietnam, opinions expressed by renowned analysts and experts (Alain C. Enthoven and Robert William Komer), which emphasized the need for a greater number of small units, which, by means of another approach, would have had better results (Sorley, 1999, pp. 8-11).

In the case of the in-depth 
understanding of the concept to which we refer, the military structures should strive to serve multiple functions/purposes. Thus, even a mechanized division of the USA has infantry battalions and other combat or support structures that can fulfil independent missions (Arquilla \& Ronfeldt, 2000, p. 56), and the new doctrinary conception of the Russian Federation stipulates the use of battalion-type tactical groups composed of one armor company, three mechanized infantry companies, one anti-tank company, two to three companies of self-propelled artillery and Multiple Launch Rocket Systems, and two air defense companies (Karber \& Thibeault, 2016). These groups of joint forces provide effectiveness, manoeuvrability and protection to operate in dispersed and decentralized environment.

On the other hand, armies can not achieve swarming if the forces remain structured the same as before, trained to fight in the classic way with a conventional adversary. It is deemed necessary to make the transition from light fighting vehicles, avoiding the heavy ones like the tank. Light combat vehicles will be organized into dispersed cells, of small dimensions, that will represent, in the vision of swarming, the new units for manoeuvre. These cells must go beyond physical collaboration, beyond simple cooperation, being an imperative for the achievement of the full integration of all the structures (perhaps in groups) and the implementation of coherent and pulsatory actions from all the directions and the concentration of effort in the right place and at the decisive moment.

The action of these cells can be truly integrated and coherent only if the structures and the elements of the leadership and coordination system would sufficiently use the options and the facilities of the information age, also applying the principles of the Network-Centric Warfare. Entering the depth of the problem (command-control), the types of hierarchies required by swarming are questioned. Given the experience of other actors in the security environment, and we refer here to terrorist organizations, to organized crime organisations or NGOs, we consider that it is appropriate that the military/security structures should adopt the network principle both for organizational design and for the leading of actions. This, of course, brings up the problem of the dissolution of the command authority. But, where possible, a solution could be hybrid structures - classic command structures with an innovative design and based on computer networks -, which should help to solve the issues raised by institutional redesign.

From the thing presented so far, it is obvious that this doctrinary concept can not be achieved without informational capabilities of surveillance and communication. This doctrinary vision will help the military organization turn into a sensory organization, while an integrated information system C4ISR (Command, Control, Communications, Computers, Information, Surveillance and Recognition) will be crucial for the interconnection of the operational units (Defense Security Cooperation Agency, 2010).

Another challenge for swarming is that of achieving logistic processes that should make sense on a battleground where the friendly forces are dispersed. A swarmingtype of force needs a very different logistics from the one that has been in use so far, in which the supply with ammunition, food, materials and other equipment has been made en masse. Within swarming, these goods and services will not be delivered to fixed locations, but they must reach units that always change their location. However, the solutions come from the fact that a swarming-type of force being small, the demand for supplies will also be diminished, which may lead to the achievement of new methods of delivery and the logistical support can be much better achieved.

\section{Conclusions}

Swarming is a maximum novelty doctrinary-operational concept with real perspectives for development, by means of the shift from mass armies to numerous 
small size units, with great firepower, remarkable mobility and which can to act on the enemy simultaneously from several directions in order to disorient them, to make it impossible to focus their effort on a certain direction, to weaken their combat capability and thus increase their vulnerability to other attacks.

In order to adopt the concept of swarming, we must analyze organisational issues in depth, issues concerning the leadership processes as well as aspects related to the integration of the new informational capabilities in the functioning of military structures. In order for swarming to function, emphasis must be put on the comprehensive approach (of all the components), this thing being seen as a necessary condition of swarming, which seeks to integrate information as well as the action capabilities of all the participants.

Besides the expansion of cooperation and even the deepening of the integration, a decentralization of the command and control of the dispersed forces that operate in a non-linear battlefield is needed.

Furthermore, the need for information of a swarming-type of force will be accomplished when a swarmingtype of operation involves concentration of the effort in the right place and at the decisive moment. Through content, this concept entails the repeated firing at the enemy or attacking them using military forces, from all directions and then regrouping these forces and repeating the cycle.

The swarming-type of force will be less visible, because it is characterized by the fact that it will be amorphous, at least in the eyes of the enemy. The small units that will be deployed in a dispersed manner will contribute to a passive yet ubiquitous image, a sort of ubiquitous invisibility. Thus, the force will be harder to detect, but it will be capable of regrouping and attacking anywhere on the battlefield without limits imposed by the front line. Such a potential, in our opinion, is specific to a swarming-type of force, the conception of which is based on a centralized approach and, at the same time, on the use of decentralized tactics and on methods of leading dispersed units.

Last, the fundamental principles and aspects of the Network-Based Warfare, which contributes significantly to interconnection and decentralization, should be implemented first. These issues provide a good chance to make the transition from a classic and hierarchical approach to warfare to an alternative paradigm in which hierarchies and hybrid command and control networks may develop.

\section{Acknowledgement}

This paper has been elaborated in accordance with the Scientific Research Plan of the Faculty of Military Science, the "Nicolae Bălcescu" Land Forces Academy of Sibiu. Translator and collaborator: Assoc.prof. Gabriela Mihăilă-Lică, PhD.

\section{REFERENCES}

Arquilla, J. \& Ronfeldt, D. (2000). Swarming \& the Future of Conflict, US, Santa Monica: RAND Corporation, National Defense Research Institute.

Bernard, W. (2015). Furnicile, Bucharest: Nemira Publishing House.

Defense Security Cooperation Agency. (2010). Iraq - Command, Control, Communications, Computers, Intelligence, Surveillance and Reconnaissance (C4ISR) Systems, available at: http://www.dsca.mil/sites/default/files/mas/iraq 10-65 0.pdf, accesed at: 15.10 .2016$. 
Gelernter, D. (1992). Mirror Worlds, or the Day Software Puts the Universe in a Shoebox ... How It Will Happen and What It Will Mean, New York: Oxford University Press.

George, G.M.T. (2014). Analiză - Situaţia militară din estul Ucrainei, available at: http://www.rumaniamilitary.ro/analiza-situatia-militara-din-estul-ucrainei, accesed at: 13.05.2015.

Griffith S.B. (2005). Mao Tse-tung on Guerrilla Warfare, Translated by Samuel B. Griffith, Mineola, New York: Dover Publications, Inc.

Heilbrunn, O. (1965). Conventional Warfare in the Nuclear Age, London: George Allen and Unwin.

Karber, P. \& Thibeault, J. (2016). Russia's New-Generation Warfare. Army Magazine, Vol. 66, No. 5, available at: http://www.armymagazine.org/2016/05/13/russias-newgeneration-warfare, accesed at: 15.10.2016.

Libicki, M. (1994). The Mesh and the Net: Speculations on Armed Conflict in a Time of Free Silicon, Washington, D.C.: National Defense University, Institute for National Strategic Studies.

OMICS International. (2014). Battle of Kursk, available at: http://research.omicsgroup.org/index.php/Battle of Kursk, accesed at: 15.10.2016.

Qiao Liang \& Wang Xiangsui. (1999). Unrestricted Warfare, available at: https://www.oodaloop.com/documents/unrestricted.pdf, accesed at: 14.10.2016.

Sorley, L. (1999). Better War: The Unexamined Victories and Final Tragedy of America's Last Years in Vietnam, Orlando, USA: Houghton Mifflin Harcourt, Inc.

Trueman, C.N. (2016). U-boats, available at: http://www.historylearningsite.co.uk/ world-war-two/war-in-the-atlantic/u-boats/, accesed at: 25.09.2016. 